\title{
Experimental Analysis of a Compressed Air Engine
}

\author{
Qihui Yu, Maolin Cai \\ School of Automation Science and Electrical Engineering, Beihang University, Beijing, China \\ Email:yqhhxq@163.com, Caimaolin@gmail.com
}

Received 20 June 2015; accepted 9 September 2015; published 16 October 2015

Copyright (C) 2015 by authors and Scientific Research Publishing Inc.

This work is licensed under the Creative Commons Attribution International License (CC BY). http://creativecommons.org/licenses/by/4.0/

CC) (i) Open Access

\begin{abstract}
Nowadays, automobiles consume a large number of fossil fuels. However, the consumption of fossil fuels has brought many serious environmental problems, such as global warming, ozone layer depletion and fine particulate matter. To avoid such environmental problems, renewable energy has been applied to automobiles. In this paper, an air-powered engine of a renewable energy vehicle is introduced. To lay a foundation for the optimization of compressed air engine (CAE), a physical model of compressed air engine (CAE) is established with cam which controls compressed air charge or discharge cylinder. To obtain performance of the CAE, a prototype CAE system is set up. The output torque, power and efficiency are obtained through experimental study. The results show that the prototype of CAE has a good economic performance under low speed and when the supply pressure is $2 \mathrm{MPa}$, the maximum output power is $1.92 \mathrm{~kW}$; the maximum output torque is $56.55 \mathrm{~N} \cdot \mathrm{m}$; and the maximum efficiency is $25 \%$. This research can be referred to in the optimization of air-powered engine.
\end{abstract}

\section{Keywords}

Prototype, Compressed Air, Experiment, Performance

\section{Introduction}

Over the recent decades, the serious environmental issues, such as greenhouse effect, ozone layer depletion and fog and haze, have drawn considerable attention. Burning of fossil fuels has been considered as the main cause of some serious environment issues [1] [2]. With respect to environmental protection, the issue of energy expenditure was emphasized [3]. Some scholars consider that the petroleum crisis will happen, which may result in ending the era of low-cost petroleum and develop the fierce competition market of the new energy automobiles. So far, the new energy automobiles, such as electric vehicles, hybrid electric vehicles, pneumatic power vehicles, 
gradually appear. The typical products of zero-pollution vehicles contain the electric vehicles, while there are toxic elements within batteries which could spew toxic fumes. Morita [4] discussed the growing modes of the power systems of future transportations. Negre et al. [5] has developed a dual energy engine employing the petrol and compressed air, and the relevant research is ongoing. The Moteur Development International (MDI) has developed a compressed air vehicle, namely, E.Volution [6]. The air tank at the bottom of E.Volution can hold 300 liters of compressed air, which can provide vehicle kinetic energy. The vehicle can travel $200 \mathrm{~km}$ at the speed of $96 \mathrm{~km} / \mathrm{h}$. And the virtue of the E.Volution is the charging process which just needs 3 minutes via a high-pressure air-charging station.

The University of Northern Texas and the University of Washington [7] work together to research on the liquid nitrogen-powered vehicles. Ordonez C.A. [8] put forwards that the perfect efficiency of liquid nitrogen-powered vehicle can attain $85 \%$ in the condition of the power cycle of the quasi-isothermal expansion liquid nitrogen. For instance, in the operating condition of the expansion pressure of $8 \mathrm{MPa}$ and rotating speed of $850 \mathrm{rpm}$, the two-cylinder engine could produce $15 \mathrm{KW}$ power and $190 \mathrm{Nm}$. A general vehicle with a two-cylinder engine could drive for $140 \mathrm{~km}$ using 200 liters of liquid nitrogen. Tokhi et al. [9] also stated clearly that, compared with the electrical motor, the virtues of pneumatic motor have shown that it can 1) conveniently gain the power source, 2) have large starting torque, and 3) handily manage rotating speed and torque: only an air-flow controller or a pressure controller is needed. Beyond these virtues, the overloading or heat coming from friction does not take place in the pneumatic motor. Xu et al. designed an exchange system for the air-powered engine [10]. Chen et al. proposed a newly electro-pneumatic valve for the compressed air-powered engine [11].

According to the above analysis, the compressed air engine (CAE) will be emphasized in the future. In this paper, an air-powered engine of a renewable energy vehicle is introduced. To lay a foundation for the optimization of CAE, a physical model of CAE is set up. To obtain performance of the CAE, a prototype CAE system is set up. And the physical model of CAE is verified by experiments. The following sections are organized as follows: the introduction to CAE is represented in Section 2; the theoretical analysis is described in Section 3; the experiment results are shown and analyzed in Section 4; and the conclusion is stated in Section 5.

\section{The Principles of CAE}

A typical single-cylinder CAE, as shown in Figure 1, is composed of an intake valve (shown by number 1), an

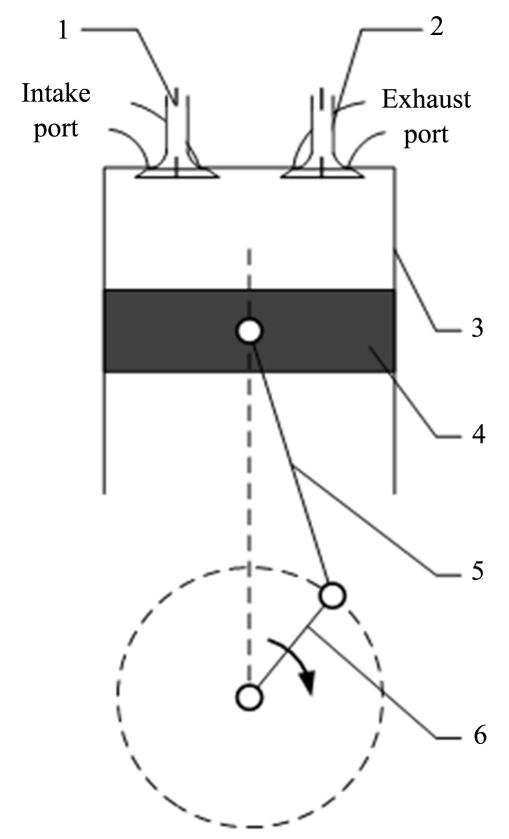

Figure 1. The construction of CAE. 1. Intake valve; 2. Exhaust valve; 3. Cylinder; 4. Piston; 5. Connecting rod; 6. Crankshaft. 
exhaust valve (indicated by number 2), a cylinder (indicated by number 3), a piston (shown by number 4), a connecting rod (shown by number 5) and a crankshaft (shown by number 6 ). In the suction power stroke, compressed air enters the cylinder via the intake valve because of the pressure difference, drives the piston downward. Then the intake valve closes when the crank reaches a certain angle. While the compressed air continues to push the piston down and output mechanical work. When the movement of piston is close to the bottom dead center (BDC) the exhaust valve opens, so that the compressed air with residual pressure is expelled by the impetus of the piston. After the piston moves back to the top center (TDC), the CAE completes a work cycle.

The schematic diagram of a CAE automobile system, as demonstrated in Figure 2, is mainly consist of a CAE, an high pressure air tank, an buffer tank, two pressure sensors, two regulators, an air operated pressure relief valve (TESCOM), an electronic proportional directional control valve (FAIRCHILD), a silencer, a signal processor. The airflow path starts from the high pressure air tank then through buffer tank, control valve and eventually accesses the CAE. The airflow mass, entries into the CAE, is controlled by the valve position. And the valve is managed by externally applied electric current, denoted by $i$, when $i$ equals to $4 \mathrm{~mA}$, the valve will be fully closed, and fully open when $i$ is equal to $20 \mathrm{~mA}$. The major parts of air dynamic system and their functions are revealed in Table 1.

\section{Thermodynamic Process and Efficiency Analysis}

\subsection{Thermodynamic Process Analysis}

For the CAE, the high pressure air at normal temperature could supply the driving force. The reason of the shaft

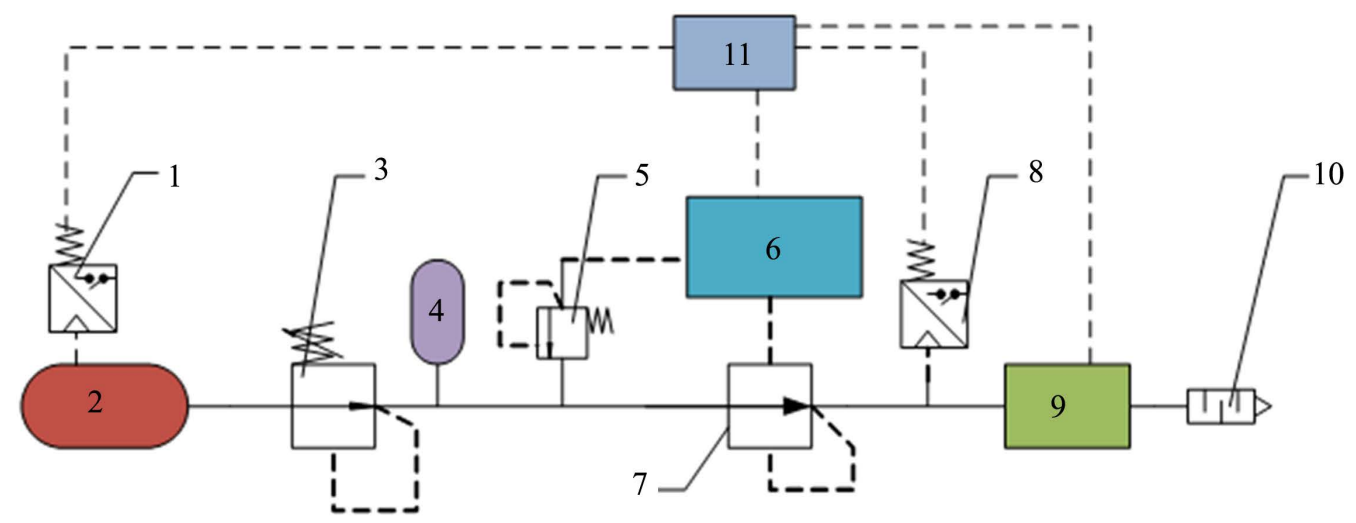

Figure 2. The ideal schematic diagram of CAE automobile.

Table 1. The equipment of CAE automobile.

\begin{tabular}{|c|c|}
\hline Elements & Function \\
\hline 1 Pressure sensor & Calculate the pressure of storage tank \\
\hline 2 High pressure air tank & Store up and provide high pressure air \\
\hline 3 Regulator & Regulate gas pressure \\
\hline 4 Buffer tank & Provide appropriate pressure air to CAE \\
\hline 5 Regulator & $\begin{array}{l}\text { Regulate gas pressure to meet electronic proportional } \\
\text { directional control valve pressure }\end{array}$ \\
\hline 6 Electronic proportional directional control valve & Modulate the amount of entering air which controls the elements 7 \\
\hline 7 Air operated regulator & Modulate the pressure of entering air and control of CAE \\
\hline 8 Pressure sensor & Calculate the pressure of airflow \\
\hline $9 \mathrm{CAE}$ & Provide the power \\
\hline 10 Silencer & Reduce exhaust noise \\
\hline 11 Controller & Measure pressure and output the analog signal to the electronic control valve \\
\hline
\end{tabular}


work is the impulse action and the dynamic action of the high compressed air. Thermodynamically, the process is considered reverse to the course of the piston-type air compressor. The ideal thermodynamic process can be shown as Figure 3, intake process and exhaust process are considered constant pressure process, and expansion process is considered adiabatic process. The theoretical work is given as follows.

$$
\begin{gathered}
W_{5-2}=p_{1}\left(V_{2}-V_{1}\right) \\
W_{2-3}=\frac{1}{1-k} p_{1} V_{2}\left[\left(\frac{V_{3}}{V_{2}}\right)^{1-\kappa}-1\right] \\
W_{3-5}=p_{4}\left(V_{1}-V_{3}\right) \\
W_{\text {out }}=W_{5-2}+W_{2-3}+W_{3-5} \\
=p_{1}\left(V_{2}-V_{1}\right)+\frac{1}{1-k} p_{1} V_{2}\left[\left(\frac{V_{3}}{V_{2}}\right)^{1-\kappa}-1\right]+p_{4}\left(V_{1}-V_{3}\right)
\end{gathered}
$$

where, $W_{\text {out }}$ is the theoretical work done, $p_{1}$ and $V_{2}$ represent the supply pressure and volume, respectively, at which the air push down the piston downward movement, $V_{1}$ is the clearance of cylinder, $p_{3}$ and $V_{3}$ are the pressure and volume, respectively, up to which the maximum expansion of air takes place, and $p_{4}$ is the pressure at which the piston discharges the air to the environment.

\subsection{Efficiency Analyses}

The CAE can be applied to transform compressed air energy into mechanical energy. The energy efficiency of CAE can be defined as two approaches. One is the ratio of the output shaft energy to the input energy of the CAE as follows [12]

$$
\eta=\frac{\omega T}{\Delta p Q}=\frac{2 \pi n T}{\Delta p Q}
$$

where $\omega$ indicates the angular speed of the CAE, $\Delta p$ indicates the different pressure from inlet to outlet of CAE, $T$ indicates the torque of the CAE, $Q$ indicates the airflow value under compressed condition and $n$ indicates the revolution per second.

The other way is shown as follows [13]

$$
\eta=\frac{\omega T}{p_{i n} Q}=\frac{2 \pi n T}{p_{i n} Q}
$$

where $p_{\text {in }}$ represents the inlet pressure.

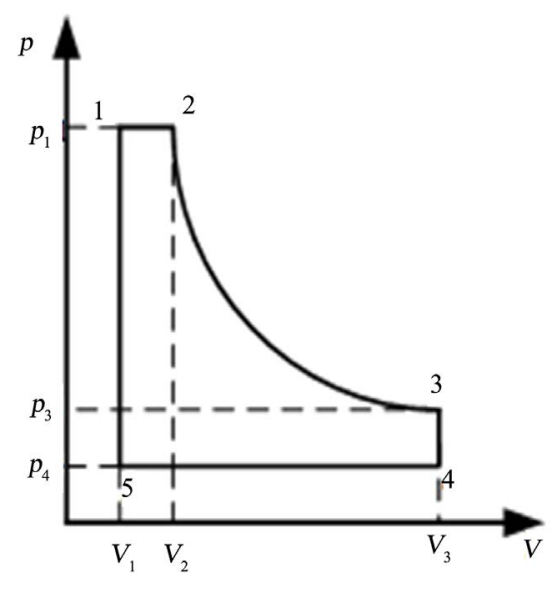

Figure 3. The ideal thermodynamic process of CAE. 
According to literature [14], the input energy of the CAE should be comprised of two parts. The first part represents the transmission power, which addresses the power required to push the air downstream. The second part represents the expansion power, which addresses the available work due to air expansion. $P_{t}$ and $P_{e}$ are used to represent these two parts, respectively, and can be calculated using the following equations.

$$
\begin{gathered}
P=P_{t}+P_{e} \\
P_{t}=\left(p-p_{a}\right) Q=p_{a} Q_{a}\left(1-\frac{p_{a}}{p}\right) \\
P_{e}=p Q \ln \frac{p}{p_{a}}-\left(p-p_{a}\right) Q=p_{a} Q_{a}\left(\ln \frac{p}{p_{a}}+\frac{p_{a}}{p}-1\right)
\end{gathered}
$$

The efficiency of a CAE is defined as follows

$$
\eta=\frac{P_{\text {out }}}{P} \times 100 \%
$$

where $P_{\text {out }}$ is the output power.

From Equations (4) and (10), it can be gotten that

$$
\eta=\frac{p_{1}\left(V_{2}-V_{1}\right)+\frac{1}{1-k} p_{1} V_{2}\left[\left(\frac{V_{3}}{V_{2}}\right)^{1-\kappa}-1\right]+p_{4}\left(V_{1}-V_{3}\right)}{p_{1} V_{2} \ln \frac{p_{1}}{p_{4}}}
$$

Employing Lagrange’s multiplier, the optimum value of efficiency will be acquired when

$$
\frac{\partial \eta}{\partial V_{2}}=0
$$

Differentiating Equation (11) with respect to $V_{2}$

$$
\left(\frac{V_{3}}{V_{2}}\right)^{-k}=\frac{p_{4}\left(V_{3}-V_{1}\right)}{V_{3} p_{1}}+\frac{V_{1}}{V_{3}}
$$

In piston-type CAE, $V_{3}$ represents the maximum volume of cylinder, $V_{1}$ represents the clearance volume of cylinder, $V_{2}$ represents the volume of intake air. $V_{2}$ can be optimized by Equation (13).

\section{Experimental Analysis}

\subsection{Test Bench}

To obtain the performance of the CAE, a piston-type prototype was designed which is shown in Figure 4. It contains cam cover, camshaft, cylinder header, exhaust valve, intake valve, piston, link, cylinder, flywheel housing, flywheel, crankshaft, oil pan, oil filter, two synchronous pulleys, etc. The CAE has one intake valve and one exhaust valve. Air cooling method is applied in the CAE.

To obtain fast response of valve moment, input flow of the CAE is controlled by cam. Valve lift and phase are determined by cam profile. The cam profile was optimized in the author's previous work [15]. The intake and exhaust cam profiles are shown in Figure 5.

In the suction power stroke, the piston is driven downward by the compressed air which flows into the cylinder through the intake valve. Linear movement of the piston is transformed to rotary motion by the way of crank-connecting rod mechanism. The intake lift and phase are decided by cam profile. When intake valve closes after reaching a specific crank angle, the piston is pushed by the compressed air inside the cylinder expansion energy until reach to the bottom dead center (BDC).

In the exhaust stroke, the exhaust valve opens so that the compressed air with residual pressure releases by the impetus of the piston. The piston is driven by flywheel energy and finally reaches the top dead center (TDC). Table 2 lists the specifications of the prototype. 


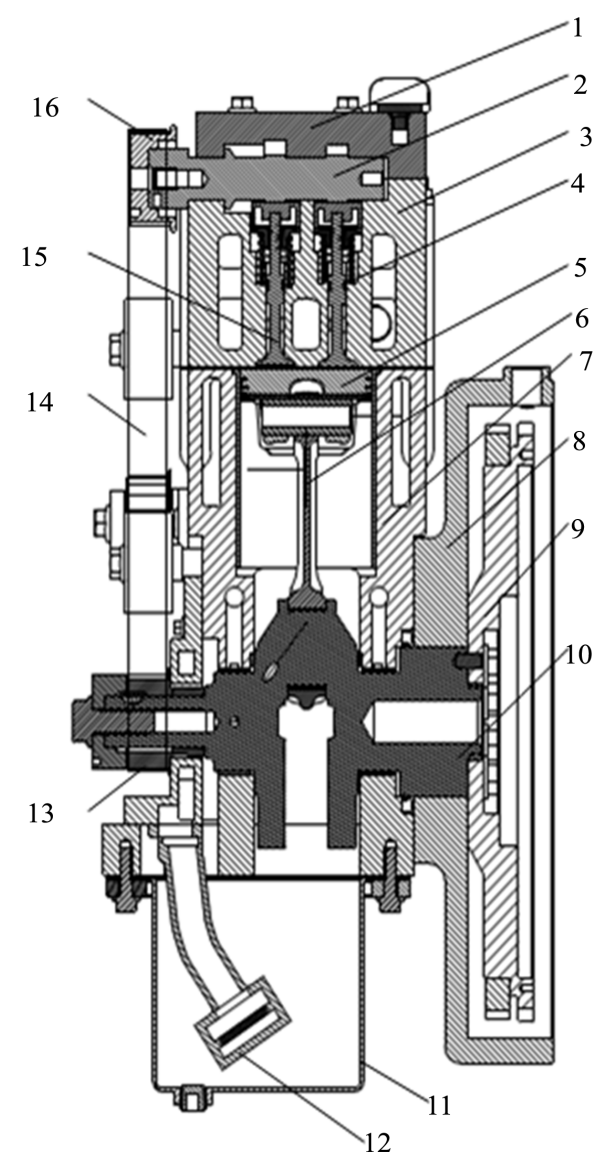

Figure 4. Piston-type of CAE. 1. Cam cover; 2. Camshaft; 3. Cylinder header; 4. Exhaust valve; 5. Piston; 6. Link; 7. Cylinder; 8. Flywheel housing; 9. Flywheel; 10. Crankshaft; 11. Oil pan; 12. Oil filter; 13. Synchronous pulley 1; 14. Synchronous belt; 15 . Intake valve; 16 . Synchronous pulley 2.

Table 2. Engine specifications.

$\begin{array}{cc}\text { Bore } & 85 \mathrm{~mm} \\ \text { Stroke } & 88 \mathrm{~mm}\end{array}$

$\begin{array}{cc}\text { Displacement } & 0.5 \mathrm{~L} \\ \text { Intake port diameter } & 12 \mathrm{~mm} \\ \text { Exhaust port diameter } & 12 \mathrm{~mm}\end{array}$

Compression ratio

10

After that a dedicated test bench for the CAE was designed and built to measure the CAE's inlet pressure, rotation speed, power, torque, flow rate and other parameters. Figure 6 shows the schematic diagram of the test bench.

\subsection{Results and Analyses}

In the experimental study, the supply pressure was adjusted by a pressure regulator, the external load was adjusted by eddy current dynamometer. The power outputs from the CAE were measured at supply gas pressures ranging from $1 \mathrm{MPa}$ to $2 \mathrm{MPa}$. 


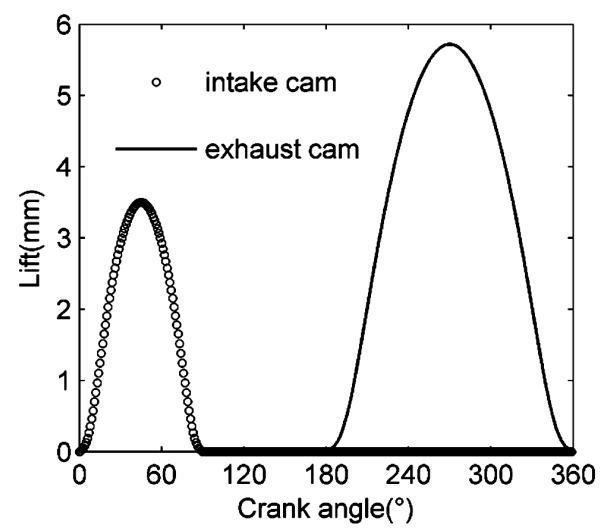

Figure 5. Intake and exhaust cam profiles.

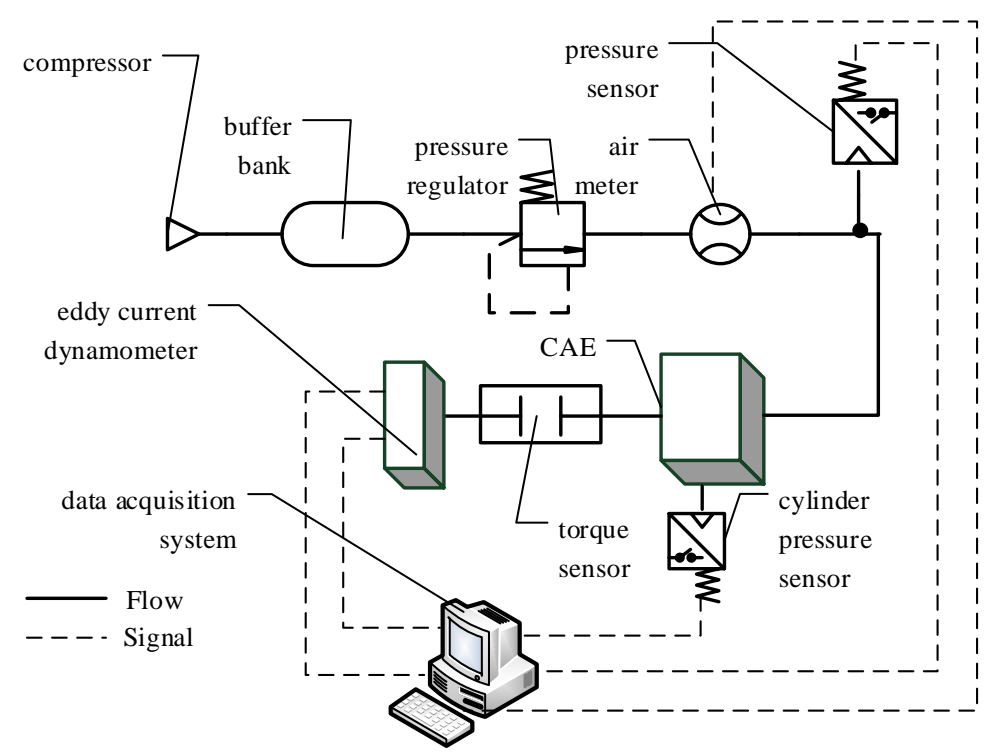

Figure 6. The schematic diagram of test bench.

The output torque is measured by torque sensor. The output power $\left(P_{\text {out }}\right)$ is calculated by following equation.

$$
P_{\text {out }}=\frac{T \times n}{9550}
$$

The mass of the supply air is measured by air meter, and the supply pressure is measured by pressure sensor. Then the air power and efficiency are calculated by Equations (9) and (10), respectively.

The output torque, output power, efficiency curves at different rotation speed and supply pressure are shown in Figures 7-9, respectively.

It can be obtained from Figures 7-9 that:

1) The output torque declines with an increase in the rotation speed, and ascends with increasing the supply pressure. The maximum torque can be obtained at the lowest rotation speed and the highest supply pressure. When the supply pressure is $2 \mathrm{MPa}$, the output torque is $56.55 \mathrm{~N} \cdot \mathrm{m}$.

The output torque is mainly determined by the cylinder pressure. In a working cycle, the cylinder pressure increases with supply pressure increasing, so the higher supply pressure, the higher output torque. And the cylinder pressure mainly is effected by the mass of intake air. It is obvious that the mass of intake air descends sharply with an increase in the engine speed.

2) At the beginning, the output power ascends sharply with the increasing rotation speed and reaches to maximum value. After this peak, the output power drops sharply. When the supply pressure is $2 \mathrm{MPa}, 1.5 \mathrm{MPa}$ 


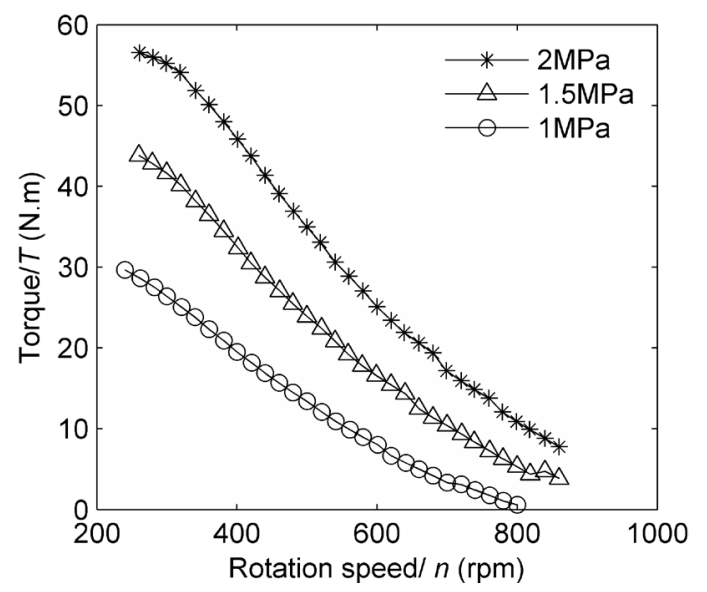

Figure 7 . The output torque at different rotation speed.

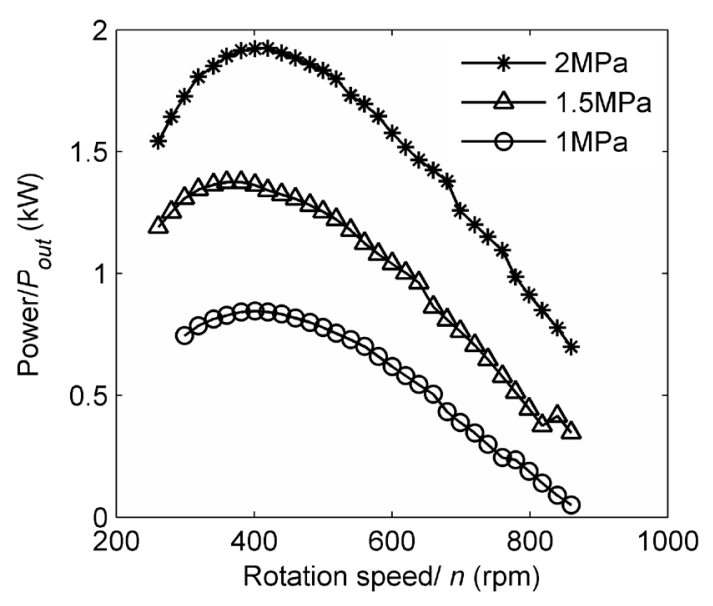

Figure 8. The output power at different rotation speed.

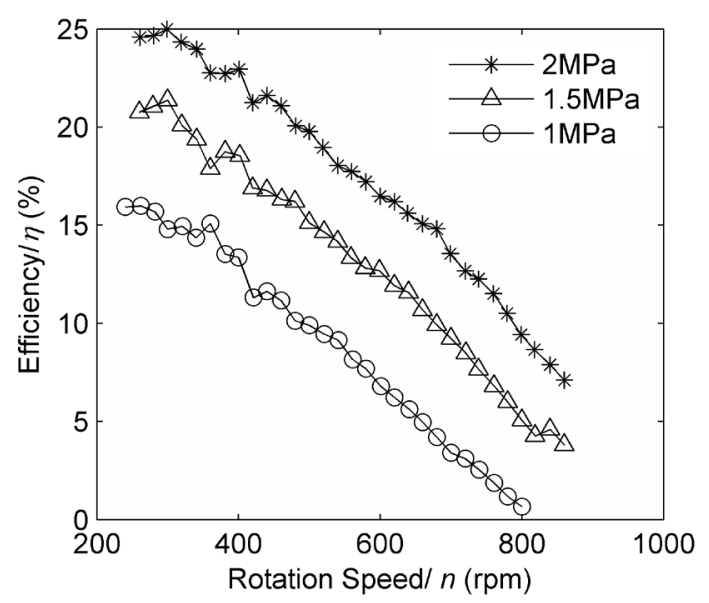

Figure 9. The efficiency at different rotation speed.

and $1 \mathrm{MPa}$, the maximum output power is $1.92 \mathrm{~kW}, 1.37 \mathrm{~kW}$ and $0.85 \mathrm{~kW}$, respectively, and the corresponding speed is $420 \mathrm{rpm}, 380 \mathrm{rpm}$ and $340 \mathrm{rpm}$, respectively.

That is because the output power is determined by the output torque and engine speed. When the engine speed is smaller than the certain speed, the output power mainly is effected by the rotation speed. When the engine is 
larger than the certain speed, the output power chiefly is influenced by the output torque.

3) The energy efficiency declines with increasing in the rotation speed and supply pressure. When the supply pressure is $2 \mathrm{MPa}$, the maximum efficiency is $25 \%$.

The main reason is that, when the CAE runs at the lower speed, the expand energy of compressed air can be made full use. Moreover, the throttle loss ascends with an increase in the rotation speed. The main energy loss comes from the throttle process, heat transfer process and exhaust process.

\section{Conclusions}

From this paper, a CAE was introduced, and thermodynamic characteristics and efficiency analysis were studied. To obtain the performances of CAE, a prototype of CAE was designed and adopted in test bench. The output power, torque and efficiency were obtained through experimental study. The conclusion is summarized as follows:

1) The performance of the CAE is mainly influenced by the rotation speed and supply pressure.

2) In the first instance, the output power ascends sharply with the increasing rotation speed and reaches to maximum value. After this peak, the output power drops sharply.

3) The prototype of CAE has a good economic performance under low speed.

4) When the supply pressure is $2 \mathrm{MPa}$, the maximum output power is $1.92 \mathrm{~kW}$; the maximum output torque is $56.55 \mathrm{~N} \cdot \mathrm{m}$; and the maximum efficiency is $25 \%$.

\section{Acknowledgements}

The authors greatly appreciate the support of the Foundation of Beijing Municipal Science \& Technology Commission. Without their support, this research could not have been completed.

\section{References}

[1] Salvi, B.L. and Subramanian, K.A. (2015) Sustainable Development of Road Transportation Sector Using Hydrogen Energy System. Renewable and Sustainable Energy Reviews, 51, 1132-1155. http://dx.doi.org/10.1016/j.rser.2015.07.030

[2] Jr, A.O.P., Costa, R.C.D., Costa, C.D.V., et al. (2013) Perspectives for the Expansion of New Renewable Energy Sources in Brazil. Renewable and Sustainable Energy Reviews, 23, 49-59. http://dx.doi.org/10.1016/j.rser.2013.02.020

[3] Chau, K.T. and Wong, Y.S. (2002) Overview of Power Management in Hybrid Electric-Vehicles. Energy Convers Manage, 45, 1953-1968. http://dx.doi.org/10.1016/S0196-8904(01)00148-0

[4] Morita, K. (2002) Automotive Power Source in 21st Century. Journal of Society of Automotive Engineers of Japan, 24, 3-7.

[5] Negre, et al. (2008) Engine with an Active Mono-Energy and/or Bi-Energy Chamber with Compressed Air and/or Additional Energy and Thermodynamic Cycle Thereof. US Patent, No.7469527B2.

[6] MDI (Moteur Development International). http://www.mdi.lu/english/2014\%20english.php

[7] Knowlen, C., Williams, J., Mattick, A.T., et al. (2002) Quasi-Isothermal Expansion Engines for Liquid Nitrogen Automotive Propulsion. http://www.aa.Washington.edu/AERP/CRYOCAR/Papers/sae97.pdf

[8] Ordonez, C.A. (2000) Liquid Nitrogen Fueled, Closed Brayton Cycle Cryogenic Heat Engine. Energy Conversion and Management, 41, 331-341. http://dx.doi.org/10.1016/S0196-8904(99)00117-X

[9] Tokhi, M.O., Al-Miskiry, M. and Brisland, M. (2001) Real Time Control of Air Motors Using a Pneumatic H-Bridge. Control Engineering Practice, 9, 449-457. http://dx.doi.org/10.1016/S0967-0661(00)00122-2

[10] Xu, Q.Y., Cai, M.L. and Shi, Y. (2014) Dynamic Heat Transfer Model for Temperature Drop Analysis and Heat Exchange System Design of the Air-Powered Engine System. Energy, 68, 877-885.

http://dx.doi.org/10.1016/j.energy.2014.02.102

[11] Chen, P.L., Yu, X.L. and Liu, L. (2009) Simulation and Experimental Study Electro-Pneumatic Valve Used in AirPowered Engine. Journal of Zhejiang University-SCIENCE A, 10, 377-383. http://dx.doi.org/10.1631/jzus.A0820373

[12] Shen, Y.T. and Hwang, Y.R. (2009) Design and Implementation of an Air-Powered Motorcycles. Applied Energy, 86, 1105-1110. http://dx.doi.org/10.1016/j.apenergy.2008.06.008

[13] Huang, C.H., Hu, C.K., Yu, C.J., et al. (2013) Experimental Investigation on the Performance of a Compressed-Air Driven Piston Engine. Energies, 6, 1731-1745. http://dx.doi.org/10.3390/en6031731 
[14] Cai, M.L., Kawashima, K. and Kagawa, T. (2006) Power Assessment of Flowing Compressed Air. Journal of Fluids Engineering, 128, 402-405. http://dx.doi.org/10.1115/1.2170129

[15] Xu, Q.Y., Shi, Y., Yu, Q.H., et al. (2014) Virtual Prototype Modeling and Performance Analysis of the Air-Powered Engine. Journal of Mechanical Engineering Science, 228, 2642-2651. http://dx.doi.org/10.1177/0954406214520818

\section{Nomenclature}

$$
\begin{aligned}
& n=\text { rotation speed }(\mathrm{rpm}) \\
& p_{1}=\text { supply pressure }(\mathrm{Pa}) \\
& p_{3}=\text { exhaust pressure }(\mathrm{Pa}) \\
& p_{4}=\text { atmosphere pressure }(\mathrm{Pa}) \\
& P=\text { air power }(\mathrm{Pa}) \\
& Q=\text { volumetric flow rate }\left(\mathrm{m}^{3} / \mathrm{s}\right) \\
& T=\text { torque }(\mathrm{N} \cdot \mathrm{m}) \\
& V_{1}=\text { clearance volume of cylinder }\left(\mathrm{m}^{3}\right) \\
& V_{2}=\text { intake air volume }\left(\mathrm{m}^{3}\right) \\
& V_{3}=\text { maximum volume of cylinder }\left(\mathrm{m}^{3}\right) \\
& W=\text { mechanical work }(\mathrm{J}) \\
& \Delta p=\text { different pressure }(\mathrm{Pa}) \\
& \omega=\text { angular speed }(\mathrm{rad} / \mathrm{s}) \\
& \kappa=\text { specific heat ratio } \\
& \eta=\text { energy efficiency }
\end{aligned}
$$

\section{Subscripts}

$$
\begin{aligned}
& e=\text { expansion power } \\
& \text { out }=\text { output power } \\
& t=\text { transmission power }
\end{aligned}
$$

